\title{
Preventing ulcer rebleeding: The role of second-look endoscopy
}

\author{
SC Sydney Chung MD FRCS(Ed) MRCPUK
}

SCS Chung. Preventing ulcer rebleeding: The role of secondlook endoscopy. Can J Gastroenterol 1999;13(5):409-411. Whether a second-look endoscopy after initial endoscopic hemostasis is of value is controversial. Routine surveillance endoscopy on the next day and treatment of any remaining stigmata may provide marginal benefit, but existing studies are not large enough to demonstrate significant differences. Endoscopic retreatment when patients develop rebleeding may allow emergency surgery to be avoided if successful but may endanger life if further bleeding occurs. Early data indicate that surgery can be avoided in about $75 \%$ of patients by retreatment without an increase in mortality.

Key Words: Endoscopy; Ulcer rebleeding

\section{Prévenir la reprise du saignement d'ulcère : Rôle de l'endoscopie de contrôle}

\begin{abstract}
RÉSUMÉ : L'utilité de l'endoscopie de contrôle après une première intervention d'hémostase endoscopique soulève la controverse. L'endoscopie de contrôle effectuée le lendemain et le traitement de tout saignement résiduel peut offrir des avantages accessoires, mais les études existantes ne sont pas suffisamment grandes pour faire état de différences significatives. Lorsque les patients se remettent à saigner, l'endoscopie de contrôle, peut permettre d'éviter la chirurgie d'urgence si elle réussit, mais peut mettre la vie du patient en danger si le saignement reprend. Selon les données préliminaires, on peut éviter le recours à la chirurgie chez environ $75 \%$ des patients par l'endoscopie de contrôle et ce, sans accroître la mortalité.
\end{abstract}

$\mathrm{I}_{\mathrm{i}}^{\mathrm{n}}$ $\mathrm{n}$ patients with ulcer hemorrhage, rebleeding in hospital increases the rate of mortality six- to 10 -fold. The rebleeding rate after initial endoscopic hemostasis is about $15 \%$. Whether second-look endoscopy can reduce the risk of rebleeding, decrease the need for salvage surgery and improve patient outcome is controversial.

\section{SURVEILLANCE ENDOSCOPY}

Most endoscopists adopt an expectant management policy after successful endoscopic therapy for bleeding ulcer. Centres in Europe, however, perform repeat endoscopy on a daily basis and treat any remaining stigmata until the ulcer base is clean. In an early randomized study by Rutgeerts et al (1), repeat treatment was shown to reduce rebleeding from 16 of 40 with one session to seven of 40 with two sessions with the use of adrenaline injection alone, from 11 of 40 to five of 40 with adrenaline and neodymium:yttrium-aluminum-garnet laser therapy, and from seven of 40 to three of 40 with injection of adrenaline and polidocanol. Villenueva et al (2) randomly assigned 52 of 104 patients with bleeding ulcers or ulcers with a nonbleeding visible vessel to second-look endoscopy or retreatment with adrenaline injection alone. A nonsignificant trend towards benefit (21\% versus 29\% rebleeding rate, $8 \%$ versus $15 \%$ requiring urgent surgery) was seen. Lin et al (3) randomly assigned patients to one of two groups after initial hemostasis of bleeding ulcers was achieved, again using adrenaline injection therapy. Sixty patients underwent second-look endoscopy within $48 \mathrm{~h} ; 25$ (41.7\%) of them with persistent stigmata received additional adrenaline injection. Fifty-five patients were assigned to observation until clinical rebleeding. The rate of permanent hemostasis was higher in the treatment group than in the control group (93\% versus $78 \%, \mathrm{P}=0.038$ ). No significant difference in mortality or need for surgery was observed between the two groups. In a prospective, randomized multicentre study, Messmann et al (4) randomly assigned 75 patients with hem-

Endoscopy Center, Prince of Wales Hospital, Chinese University of Hong Kong, Shatin, NT

Correspondence: Dr SC Sydney Chung, Endoscopy Center, Prince of Wales Hospital, Chinese University of Hong Kong,

Shatin, NT. Telephone 8522632 2624 30,fax 8522637 7974, e-mail sydneychung@cuhk.edu.hk 
orrhage from gastric and duodenal ulcers (Forrest class I, IIa and IIb) to scheduled daily retreatment or observation. Patients in the treatment group received daily injection therapy with adrenaline and fibrin until endoscopy revealed a class IIc or III ulcer. No significant difference was observed in the number of blood units transfused, the length of hospital stay, episodes of recurrent bleeding or deaths.

The literature indicates that scheduled endoscopic retreatment may confer a small benefit. Whether this benefit can be shown to be significant in a randomized, controlled trial depends on the sample size, the patients entered and the mode of endoscopic treatment. Assuming a rebleeding rate of $15 \%$ following primary endoscopic treatment, a sample size of 79 patients in each arm is required to detect a $10 \%$ difference in rebleeding rate (ie, $15 \%$ to $10 \%$, alpha $=0.05$, beta $=0.2$, two-sided). A total of 363 patients are required in each arm to detect a difference of $5 \%$. If patients with low risks of rebleeding are entered, or if the endoscopic therapy is so efficient that the rebleeding rate is substantially lower, impossibly large numbers of patients need to be randomly assigned to show a difference. Adrenaline injection, although highly effective in controlling active hemorrhage, does not induce thrombosis in the blood vessel. Evidence in the literature indicates that adding a second modality (heat probe or fibrin glue) improves the results $(5,6)$. With improved primary endoscopic treatment resulting in a lower rebleeding rate, the yield from second-look endoscopy is likely to diminish further.

In a large scale European trial (7), 854 patients with actively bleeding ulcers or ulcers with nonbleeding visible vessels were randomly assigned to receive a single injection of $1 \%$ polidocanol, a single injection of fibrin glue, or daily fibrin glue injections until disappearance of vessels from ulcer craters. The rebleeding rate was significantly lower with repeated injection of fibrin glue (41 of 270 [15.2\%]) than with polidocanol alone (58 of 254 [22.8\%]). Rebleeding rate following single fibrin injection (51 of 266 [19.2\%]) was, however, not significantly lower than that following polidocanol injection alone. The mean number of endoscopy sessions in the repeated fibrin injections group was 1.7. About half of the rebleeding episodes in the authors' experience occurred in the first $12 \mathrm{~h}$ after the index endoscopy. They suggested that surveillance endoscopy be performed within this period. The strength of this trial is the large sample size. Unfortunately it is impossible to determine whether the good results of repeated fibrin glue injection are because of the use of fibrin glue per se or because of repeated injections.

Endoscopic retreatment is not without risks. Sclerosants may cause extensive gastric wall necrosis. Thrombogenic agents such as thrombin and fibrin glue are theoretically ideal because they are not tissue damaging. Contact thermal devices should be used with a great deal of caution. In our recent randomized study comparing endoscopic retreatment with surgery in rebleeding patients (8), perforations from repeated heater probe use occurred in two of 44 patients $(4.5 \%)$. Both were duodenal ulcers in the anterior wall. The use of repeat heater probes in larger chronic ulcers is para- doxically safe because these ulcers are often penetrating and involve subserosal tissue matted with fibrous tissue.

Whether it is worthwhile to perform surveillance endoscopy the next morning is unclear. Any benefit derived is likely to be small, and large numbers of patients would be endoscoped unnecessarily. No cost effectiveness analysis on this issue has been reported. If patients who are likely to rebleed can be reliably identified, surveillance endoscopy for this high risk group becomes more attractive. Factors that predict failure after endoscopic therapy have been reported $(9,10)$. Saeed et al $(10)$ used the Baylor Bleeding Score, based on clinical and endoscopic parameters, to select high risk patients. In a randomized trial, no rebleeding was observed in the retreatment group compared with five of $21 \mathrm{pa}$ tients who did not receive retreatment $(\mathrm{P}<0.05)(11)$.

\section{SECOND-LOOK ENDOSCOPY FOR REBLEEDING}

Most protocols for ulcer bleeding management mandate surgical intervention if clinically significant rebleeding develops after apparently successful endoscopic hemostasis. Surgery is the most definitive way of controlling bleeding and gives good results if performed early. Proponents of early surgical intervention point out that elderly patients poorly withstand repeated episodes of hypovolemia and shock. On the other hand, the elderly with multiple medical conditions also tolerate anesthesia and surgery poorly, and are poor candidates for rehabilitation. The knowledge that eradication of Helicobacter pylori prevents recurrent ulceration and, therefore, rebleeding has also changed the philosophy of surgery for peptic ulcer bleeding because it is no longer necessary to perform acid reduction procedures to cure the ulcer diathesis. To 'have one more go' with endoscopy when the patient rebleeds is a temptation that all endoscopists have been exposed to.

Our group performed a randomized, controlled trial comparing repeat endoscopic treatment with emergency surgery for rebleeding after endoscopic hemostasis. From 1994 to 1997, 2685 patients with ulcer bleeding were admitted to the Prince of Wales Hospital, Hong Kong. Of these, 913 underwent endoscopic hemostasis with adrenaline injection followed by heat probe. Ninety four patients $(10.3 \%)$ rebled. Excluding patients with terminal illnesses and malignant ulcers, 89 were entered into the trial. Of the patients randomly assigned to receive repeat endoscopy (adrenaline injection plus heat probe) $75 \%$ achieved permanent hemostasis. Mortality rates ( $15 \%$ for repeat endoscopy and $17.5 \%$ for surgery) were similar in both groups. Complications (12 versus 29, $\mathrm{P}=0.03$ ) were higher in the surgery group. Shock and an ulcer bigger than $2 \mathrm{~cm}$ predicted failure of repeat endoscopic therapy (8).

\section{REFERENCES}

1. Rutgeerts P, Vantrappen G, Broeckaert L, Coremans G, Janssens J, Hiele M. Comparison of endoscopic polidocanol injection and YAG laser therapy for bleeding peptic ulcers. Lancet 1989;i:1164-7.

2. Villanueva C, Balanzo J, Torras X, Soriano G, Sainz S, Vilardell F. Value of a second look endoscopy after injection therapy for bleeding peptic ulcer: a prospective and randomized trial. Gastrointest Endosc 1994:40:34-9. 
3. Lin CK, Lai KH, Lo GH, et al. The value of second-look endoscopy after endoscopic injection therapy for bleeding peptic ulcer. Gastroenterology 1996;110:A177. (Abst)

4. Messmann H, Schaller P, Gross V, et al. Can an early second-look endoscopy reduce recurrent bleeding of gastric or duodenal ulcers? Gastrointest Endosc 1996;43:354. (Abst)

5. Kubba A, Murphy W, Palmer KR. Endoscopic injection for bleeding peptic ulcer: a comparison of adrenaline alone with adrenaline plus human thrombin. Gastroenterology 1996;111:623-8.

6. Chung SCS, Lau JYW, Sung JJY, et al. Randomised comparison between adrenaline injection alone and adrenaline injection plus heat probe treatment for actively bleeding ulcers. BMJ 1997;314:1307-11.

7. Rutgeerts P, Rauws E, Swain P, et al. Randomised trial of single and repeated fibrin glue compared with injection of polidocanol in treatment of bleeding peptic ulcer. Lancet 1997;350:692-6.
8. Lau JYW, Sung JJY, Chan ACW, et al. Repeat endoscopic treatment (ET) or surgery in the management of patients with rebleeding peptic ulcers after initial endoscopic hemostasis: a prospective randomized controlled trial. Gastrointest Endosc 1998;47:87. (Abst)

9. Brullet E, Calvet X, Campo R, Rue M, Catot L, Donoso L. Factors predicting failure of endoscopic injection therapy in bleeding duodenal ulcer. Gastrointest Endosc 1996;43:111-6.

10. Saeed ZA, Ramirez FC, Hepps KS, Cole RA, Graham DY. Prospective validation of the Baylor bleeding score for predicting the likelihood of rebleeding after endoscopic hemostasis of peptic ulcers. Gastrointest Endosc 1995;41:561-5.

11. Saeed ZA, Cole RA, Ramirez FC, Schneider FE, Hepps KS, Graham DY. Endoscopic retreatment after successful initial hemostasis prevents ulcer rebleeding: a prospective randomized trial. Endoscopy 1996;28:288-94. 


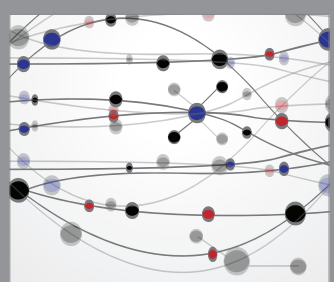

The Scientific World Journal
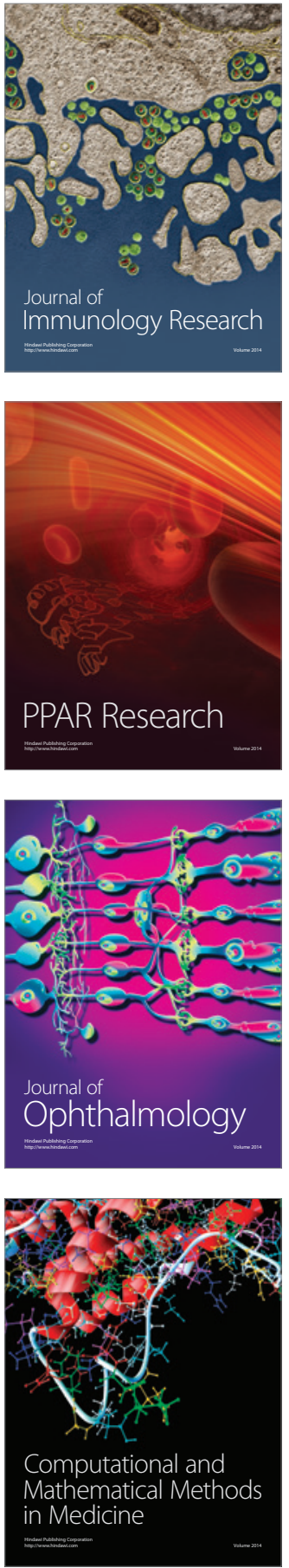

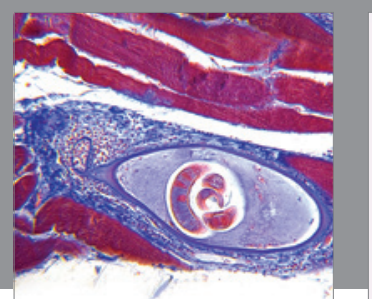

Gastroenterology Research and Practice

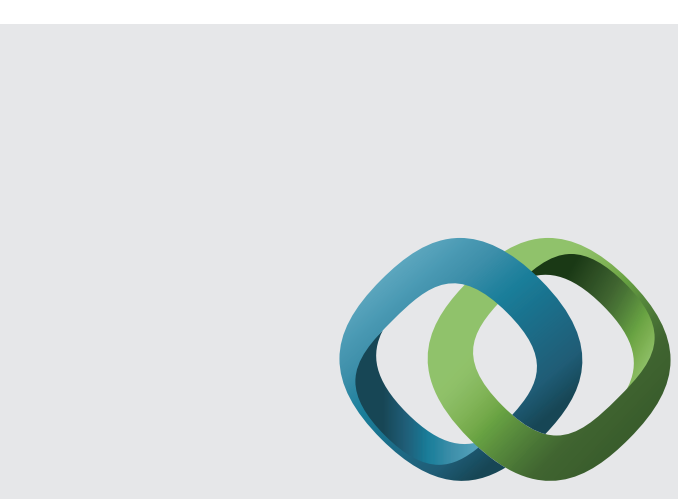

\section{Hindawi}

Submit your manuscripts at

http://www.hindawi.com
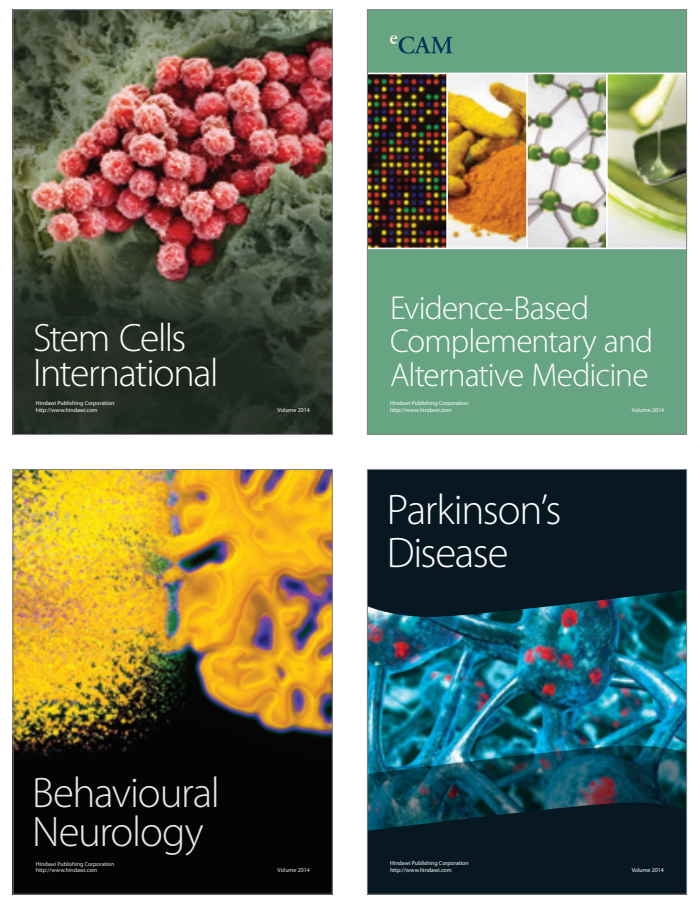
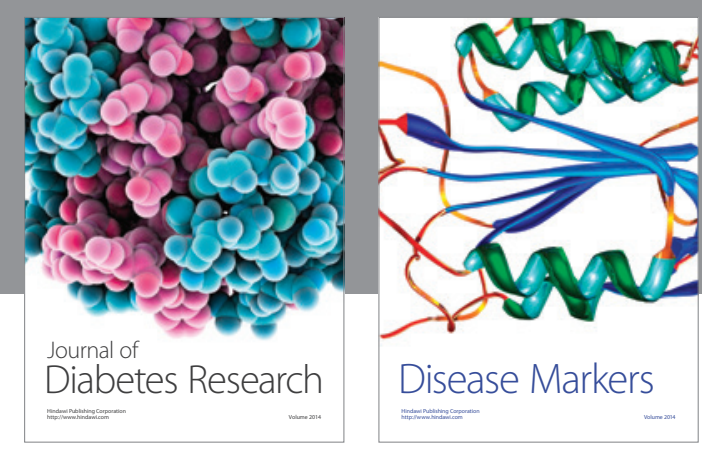

Disease Markers
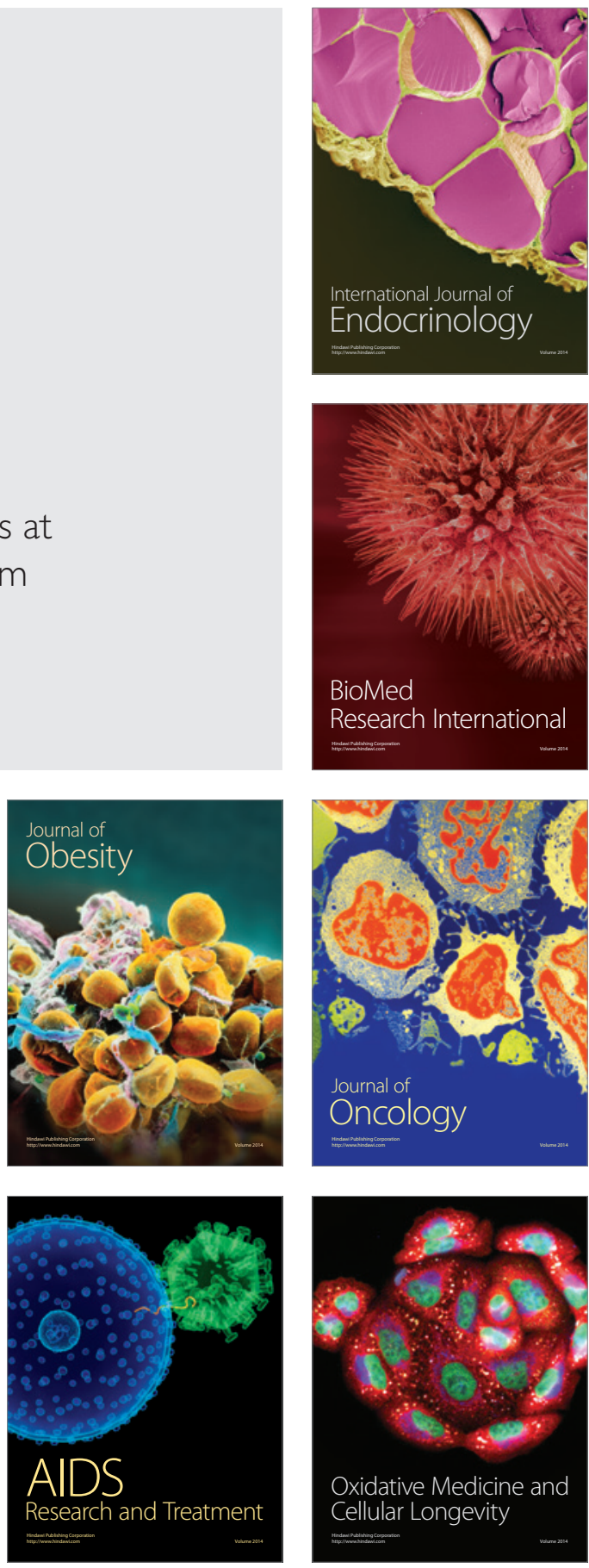